\title{
Energy balance and liver respiratory activity in rats fed on an energy-dense diet
}

\author{
BY SUSANNA IOSSA, MARIA P. MOLLICA, LILLÀ LIONETTI, \\ ANTONIO BARLETTA AND GIOVANNA LIVERINI* \\ Department of General and Environmental Physiology, University of Naples "FEDERICO II", \\ Naples, Italy
}

(Received 27 December 1995 - Revised 28 March 1996 - Accepted 26 April 1996)

\begin{abstract}
In the present study energy balance and liver respiratory activity were studied in rats fed on either a control diet or an energy-dense diet. Liver respiration was assessed both without added substrates and after the addition of hexanoate, glycerol, or sorbitol. The effect of ouabain on hexanoatesupported respiration was also determined. Metabolizable energy intake and energy expenditure increased in rats fed on an energy dense diet, but body-weight gain, as well as lipid and protein content, remained unchanged. When net energy expenditure, obtained excluding the total cost of storage, was expressed as a percentage of metabolizable energy, significant differences were found between the two groups of rats. This finding supports the presence of regulatory mechanisms in rats fed on an energy-dense diet, which are useful to counteract development of obesity. In addition, a significant increase in liver respiratory activity was found in rats fed on an energy-dense diet, both in the basal state and in that stimulated by added substrates. $\mathrm{Na} / \mathrm{K}$-pump-dependent $\mathrm{O}_{2}$ consumption also increased in rats fed on an energy-dense diet. The results indicate that a greater production of metabolic beat by the liver can contribute to the increased energy expenditure found in rats fed on an energy-dense diet.
\end{abstract}

Energy balance: Liver respiration: Fat intake

Many factors can influence energy expenditure and energetic efficiency. It is well known that starvation (Ma \& Foster, 1986; Griggio et al. 1992) and food restriction (Garrow, 1986; Hill et al. 1988; Dulloo \& Girardier, 1993) are characterized by reduced basal energy requirements, thus conserving body energy stores. On the other hand, hyperphagia may elicit a regulatory increase in energy expenditure, particularly in young rats, which therefore fail to exhibit excess weight gain (Rothwell \& Stock, 1982). The regulatory increase in energy expenditure can be induced by varying dietary composition, for example by reducing the protein content of the diet (Rothwell et al. 1982), or by presenting rats with a cafeteria diet (Rothwell \& Stock, 1982) and a high-fat low-carbohydrate energy-dense diet (Liverini et al. 1994, 1995; Iossa et al. 1995). It has been shown that brown adipose tissue and liver metabolic activities are increased in rats fed on low-protein (Tyzbir et al. 1981; Rothwell et al. 1982) and cafeteria (Berry et al. 1985; Rothwell \& Stock, 1986; Ma et al. 1987) diets. We have previously shown an increase in $\mathrm{FADH}_{2}$ oxidation and a decrease in NADH oxidation in hepatic mitochondria from rats fed on an energy-dense diet (Liverini et al. 1994; Iossa et al. 1995).

In view of these results, it appeared of interest to study liver respiratory activity in rats fed on an energy-dense diet. For this purpose, together with full energy balance 
measurements, we assessed the respiration under different conditions of stimulation in isolated hepatocytes derived from rats fed on an energy-dense diet. We also measured hepatic $\mathrm{Na} / \mathrm{K}$-pump-dependent $\mathrm{O}_{2}$ consumption in rats fed on an energy-dense diet.

\section{MATERIALS AND METHODS}

Male Wistar rats with a mean initial body weight of about $80 \mathrm{~g}$ were chosen for the experiments. They were housed individually in grid-bottomed cages at $24^{\circ}$ under an artificial circadian $12 \mathrm{~h}$ light-12 h darkness cycle. Two groups of ten rats were used. A control group (C) was fed ad libitum on a standard stock diet (Mucedola 4RF21, Settimo Milanese, Milan, Italy). The composition (\% energy) of this diet was protein 29.0, lipid 10.6 , and carbohydrate 60.4 ; its gross energy density was $15.88 \mathrm{~kJ} / \mathrm{g}$ wet weight. The second group (ED) had free access to a composite energy-dense diet; the composition of this diet is reported in Table 1 . This diet was characterized by a high fat content and by the presence of a meat component which is among the flavours most preferred by rats (Naim $e$ al. 1985; Allard \& LeBlanc, 1988). The experiment lasted $15 \mathrm{~d}$. Animal care, housing and killing met the guidelines of the Italian Health Ministry.

At the end of the experimental period, five rats from each group were used for energy balance measurements and serum free fatty acid (FFA) and triacylglycerol determinations, while the other five rats were used for hepatocyte preparation.

\section{Energy balance measurements}

Body weights and feed intakes were monitored daily to allow calculations of body-weight gain and gross energy intake. The faeces were also collected daily for energy content measurements. The collected faeces were dried and ground to a powder before determining their energy content with a bomb calorimeter (Parr adiabatic calorimeter (Parr Instrument Co., Moline, IL, USA) calibrated with dry benzoic acid standard). The gross energy content of control and energy-dense diets was also determined by the bomb calorimeter.

Digestible energy intake (taking into account the feed spillage) was obtained by subtracting the energy measured in the faeces from the gross energy intake as measured from daily feed consumption. Metabolizable energy (ME) intake was expressed as

Table 1. Composition of the energy-dense diet $(\mathrm{g} / \mathrm{kg})$

\begin{tabular}{ll}
\hline \hline Component & \\
\hline Control diet & 280 \\
Lyophilized meat* & 395 \\
Butter $\dagger$ & 178 \\
Alphacel (cellulose) & 120 \\
AIN 76 mineral mix $\ddagger$ & 20 \\
AIN 76 vitamin mix $\&$ (kJ/g) & 7 \\
Gross energy density & 19.85 \\
Percentage of energy from: & 29 \\
protein & 50 \\
lipid & 21 \\
carbohydrate & 50 \\
\hline \hline
\end{tabular}

\footnotetext{
*Liomellin, STAR s.p.a., Milan, Italy, containing (in $10 \mathrm{~g}$ ): $5.8 \mathrm{~g}$ protein $(\mathrm{N} \times 6.25$ ), $1.2 \mathrm{~g}$ lipid, $2.57 \mathrm{~g}$ carbohydrate, $0.2 \mathrm{~g}$ minerals, $0.2 \mathrm{~g}$ water.

$\dagger$ Lurpak, Denmark, locally purchased, containing $100 \mathrm{~g}$ water $/ \mathrm{kg}$.

$¥$ American Institute of Nutrition (1977).

\$American Institute of Nutrition (1980).
} 
digestible energy intake $\times 0.96$ (Barr \& McCracken, 1984). The gain in energy was obtained by subtracting the energy content of an initial group (five rats killed at the beginning of the study) from that of each of the two experimental groups. At the end of the experiment the animals were anaesthetized by an intraperitoneal injection of chloral hydrate $(400 \mathrm{mg} / \mathrm{kg}$ body weight), and blood was collected. Then, after gut content removal, the carcasses were autoclaved, chopped into small pieces, thoroughly mixed, and homogenized in water (final volumes equal to twice the carcass weight) with a Polytron homogenizer (Kinematica AG, Luzern, Switzerland). Samples of homogenates were desiccated into a dry powder from which small pellets (about $200 \mathrm{mg}$ ) were made. The energy content was measured with the bomb calorimeter. Energy expenditure was calculated from the difference between ME intake and energy gain.

\section{Circulating triacylglycerol and free fatty acid concentrations}

Serum samples were stored at $-20^{\circ}$ until analysis. Triacylglycerols were measured using the lipase-glycerol kinase method, and FFA using the acyl-CoA synthetase-acyl-CoA oxidase method. The measurements were made using the enzymic kits obtained from Boehringer-Mannheim Biochemia, Milan, Italy.

\section{Preparation and incubation of liver cells}

Rat liver cells were prepared from 16-h-fasted rats as described by Seglen (1974), except that the rats were anaesthesized by an intraperitoneal injection of chloral hydrate ( $400 \mathrm{mg} / \mathrm{kg}$ body weight). The hepatocytes were washed and suspended in a medium containing $120 \mathrm{mM}-\mathrm{NaCl}, 5 \mathrm{mM}-\mathrm{KCl}, 50 \mathrm{mM}-\mathrm{Hepes}, 1 \mathrm{mM} \mathrm{KH}_{2} \mathrm{PO}_{4}, 2 \mathrm{mM} \mathrm{CaCl}$, $1.2 \mathrm{mM} \mathrm{MgSO}$, and $20 \mathrm{~g} / 1$ fatty-acid-free bovine serum albumin. The final cell suspension was counted with trypan blue in a Burker chamber in order to assess the viability (routinely $>90 \%$ ).

Hepatocyte $\mathrm{O}_{2}$ consumption was measured polarographically with a Clark-type electrode maintained in a chamber at $37^{\circ}$. Portions corresponding to about $10^{6}$ viable cells were incubated in the suspension buffer with different substrates, at the concentrations reported in Fig. 1.

\section{Statistical analysis}

The data are summarized using means with their standard errors of five different rats. Statistical significance between the means was examined by two-tailed Student's $t$ test or by two-way ANOVA (only for main effects) followed by two-tailed Student's $t$ test. Probability values less than 0.05 were considered to indicate a significant difference.

\section{Materials}

Collagenase (EC 3.4.24.3, type IV), hexanoate, glycerol, sorbitol, and ouabain were purchased from Sigma Chemical Co., St Louis, MO, USA. All other reagents were of the highest purity commercially available.

\section{RESULTS}

Table 2 shows the results of body weight and carcass content measurements in $\mathrm{C}$ and $\mathrm{ED}$ rats. Initial body weight, final body weight, and weight gain did not differ significantly between the two groups. At the end of the experimental period, carcass lipid content was 


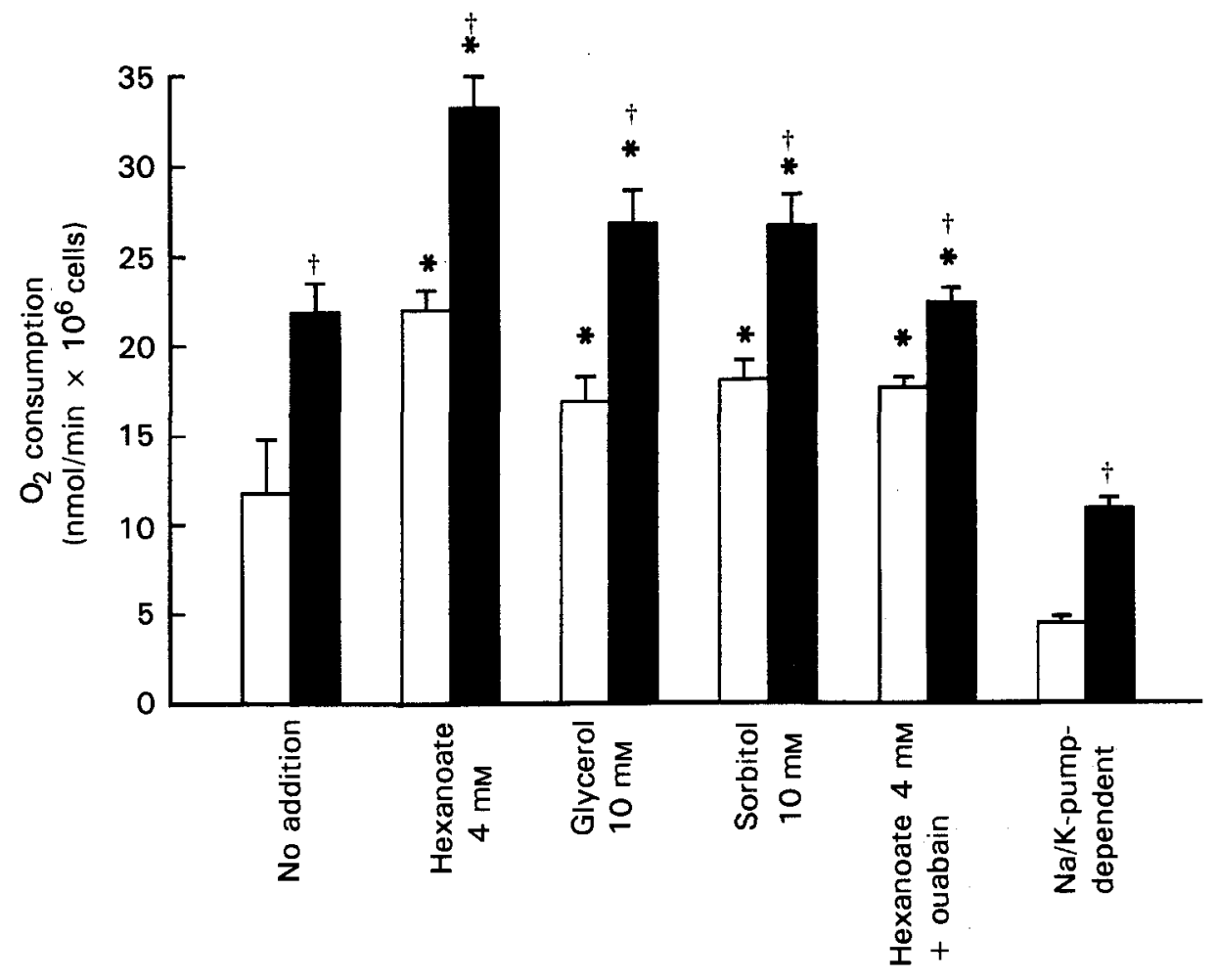

Fig. 1. Hepatocyte respiration in rats fed on control ( $\square$ ) and energy-dense ( $\square$ ) diets. Values are means with their standard errors represented by vertical bars for five rats. *Significant effect $(P<0.05)$ of addition (two-way ANOVA followed by two-tailed Student's $t$ test). $†$ Significant effect $(P<0.05)$ of diet (two-way ANOVA followed by two-tailed Student's $t$ test).

about $120 \mathrm{~g} / \mathrm{kg}$ and carcass protein content was about $210 \mathrm{~g} / \mathrm{kg}$, both in $\mathrm{C}$ and ED rats. Table 2 also gives the results of energy balance measurements in the two groups of rats. The ME intake and energy expenditure of ED rats were significantly different $(+30 \%$ and $+51 \%$ respectively) from those of $\mathrm{C}$ rats, whereas the gain in body energy was not different between the two groups. Consequently, gross efficiency was significantly lower $(-25 \%)$ in ED rats than in $\mathrm{C}$ rats. The total cost of storage was determined taking into account that the energy loss in storing $1 \mathrm{~kJ}$ of protein is $1.25 \mathrm{~kJ}$ (Pullar \& Webster, 1977), while the corresponding energy cost for fat deposition is $0.36 \mathrm{~kJ} / \mathrm{kJ}$ for diets with a high percentage of carbohydrates, such as the control diet, and $0.16 \mathrm{~kJ} / \mathrm{kJ}$ for diets with a high fat content, such as the energy-dense diet (Pullar \& Webster, 1977). The values obtained for energy expenditure excluding the total cost of storage, called net energy expenditure (NEE), are reported in the same table and were significantly higher $(+131 \%)$ in ED rats than in $\mathrm{C}$ rats. When NEE was expressed as a percentage of ME, a significant increase $(+77 \%)$ was found in ED rats compared with $\mathrm{C}$ rats (Table 2).

The $\mathrm{O}_{2}$ consumption in isolated hepatocytes from $\mathrm{C}$ and $\mathrm{ED}$ rats was measured under different conditions of stimulation of mitochondrial respiration (Fig. 1). When the cells were provided with additional substrates, namely hexanoate, glycerol or sorbitol, a significant increase in $\mathrm{O}_{2}$ consumption for the two groups occurred in comparison with respective basal states (hepatocytes incubated without added substrates). Liver cells from 
Table 2. Energy balance in rats fed on a control (C) diet or an energy-dense (ED) diet (Mean values with their standard errors for five rats over a $15 \mathrm{~d}$ period)

\begin{tabular}{|c|c|c|c|c|}
\hline \multirow[t]{2}{*}{ Diet... } & \multicolumn{2}{|c|}{$\mathrm{C}$} & \multicolumn{2}{|c|}{ ED } \\
\hline & Mean & SE & Mean & SE \\
\hline Initial body wt (g) & 75 & 2 & 75 & 2 \\
\hline Final body wt (g) & 190 & 4 & 189 & 2 \\
\hline Body-wt gain (g) & 115 & 2 & 114 & 2 \\
\hline Carcass lipid content $(\mathrm{g} / \mathrm{kg})$ & 114 & 5 & 119 & 8 \\
\hline Carcass protein content $(\mathrm{g} / \mathrm{kg})$ & 224 & 5 & 205 & 14 \\
\hline Metabolizable energy (ME) intake (kJ) & 2547 & 165 & $3320^{*}$ & 111 \\
\hline Body energy gain $(\mathrm{kJ})$ & 1012 & 56 & 1000 & 55 \\
\hline Energy expenditure $(\mathrm{kJ})$ & 1535 & 163 & $2320^{*}$ & 165 \\
\hline Gross efficiency $\%$ & 40 & 3 & $30^{*}$ & 3 \\
\hline Storage cost, protein $\ddagger(\mathrm{kJ})$ & 572 & 62 & 461 & 23 \\
\hline Storage cost, fat $\S(\mathrm{kJ})$ & 199 & 15 & $93^{*}$ & 8 \\
\hline Total cost of storage $(\mathrm{kJ})$ & 771 & 69 & $554^{*}$ & 22 \\
\hline Net energy expenditure $\|(\mathrm{NEE})(\mathrm{kJ})$ & 764 & 52 & $1766^{*}$ & 175 \\
\hline NEE/ME intake $\times 100$ & 30 & 4 & $53^{*}$ & 3 \\
\hline
\end{tabular}

*Mean values were significantly different from those for controls, $P<0.05$ (two-tailed Student's $t$ test).

t(Body energy gain/ME intake) $\times 100$.

$\ddagger$ Value of $1.25 \mathrm{~kJ} / \mathrm{kJ}$ was used to estimate the storage cost of protein.

$\S$ Values of $0.36 \mathrm{~kJ} / \mathrm{kJ}$ (control diet) and $0.16 \mathrm{~kJ} / \mathrm{kJ}$ (energy-dense diet) were used to estimate the storage cost of fat.

||Energy expenditure excluding the total cost of storage.

ED rats, incubated with or without added substrates, exhibited a significantly higher $\mathrm{O}_{2}$ consumption than those from $\mathrm{C}$ rats.

Fig. 1 also shows the effect of ouabain on hexanoate-supported respiration. The decrease in $\mathrm{O}_{2}$ consumption due to the specific $\mathrm{Na} / \mathrm{K}$-ATPase ( $E C$ 3.6.1.37) inhibitor, ouabain, was significantly higher in ED rats than in $\mathrm{C}$ rats. Therefore, in ED rats the $\mathrm{Na} / \mathrm{K}$-pump-dependent $\mathrm{O}_{2}$ consumption increased significantly $(+148 \%)$.

Serum triacylglycerol concentrations were 1.33 (SE 0.10) and 2.00 (SE 0.10) $\mathrm{mM}$ in C and ED rats respectively, and FFA concentrations were 0.60 (SE 0.03) and 0.83 (SE 0.02) $\mathrm{mM}$ in $\mathrm{C}$ and $\mathrm{ED}$ rats respectively. Concentrations of both variables were significantly higher $(+50 \%$ and $+38 \%$ respectively) in ED rats than in $\mathrm{C}$ rats.

\section{DISCUSSION}

Rats fed on the energy-dense diet showed increases in ME intake, energy expenditure and NEE (Table 2). When the NEE was expressed as a percentage of ME the values obtained in the two groups were significantly different. This finding indicates that the NEE : ME ratio is not constant whatever the energy intake and suggests the presence of regulatory mechanisms controlled by ME intake, which are useful to limit fat gain. The last result is different from those obtained by LeBlanc et al. (1986), who found no variation in NEE : ME ratio in rats fed on a cafeteria diet.

In the present study we have also found that feeding rats on the energy-dense diet resulted in significant increases in liver respiratory activity (Fig. 1). The respiration values of isolated hepatocytes indicate that $\mathrm{O}_{2}$ consumption measured without exogenous substrates depends not only on the ATP : ADP ratio, as is generally believed (Schwenke et al. 1981; Soboll \& Stucki, 1985), but also on the supply of substrate to the electron 
transport chain (Nobes et al. 1990). In fact, the addition of substrates which generate reducing equivalents into the mitochondria (hexanoate) or into the cytoplasm (glycerol and sorbitol) increased endogenous respiration in both groups of rats (Fig. 1). On the other hand, liver respiration with added substrates is essentially controlled by the intracellular ATP : ADP ratio; consistent with this, we have shown previously that the addition of lactate, which stimulates gluconeogenesis and hence ATP hydrolysis, causes a further increase in respiration (Iossa et al. 1991). The results obtained for liver respiration in ED rats show a significant increase both in basal state (without exogenous substrate) and in the presence of added substrates (Fig. 1). These results are in agreement with previous ones obtained with hepatocytes from rats fed on a cafeteria diet (Berry et al. 1985). The observed increase in basal respiration may be due to an improvement in substrate supply, which would be consistent with the increase in serum FFA concentrations found in ED rats. On the other hand, the increase in liver respiration in the presence of added substrates may be due to a greater ADP availability. In line with this, our results show that the $\mathrm{Na} / \mathrm{K}$ pump-dependent $\mathrm{O}_{2}$ consumption was significantly higher in ED rats than in $\mathrm{C}$ rats (Fig. 1). It should be noted that about $57 \%$ of the increased hepatocyte respiration in ED rats is directly attributable to increased $\mathrm{Na}$ pumping activity, which in turn elicits a greater liberation of metabolic heat. This increased heat production is in good agreement with the increased energy expenditure found in ED rats (Table 2).

Additional metabolic implications could come from the observation of the increase in hepatic respiration not only with glycerol and sorbitol, whose oxidation is known to be linked mainly to $\mathrm{FADH}_{2}$ oxidation (Berry et al. 1973), but also with hexanoate, whose oxidation is strictly dependent on the mitochondrial NADH levels (Sherratt \& Spurway, 1994). In fact, taking into account the impairment of NADH-dehydrogenase (EC 1.6.5.3) previously found in mitochondria isolated from ED rats (Iossa et al. 1995), the present increase in hepatic respiration is in line with our previous hypothesis (Iossa et al. 1995). Based on the increase in mitochondrial NADH:NAD ratio which occurs in ED rats (Iossa et al. 1995), we have suggested a shift of the reaction catalysed by malate dehydrogenase (EC 1.1.1.37) in favour of malate production at the expense of oxaloacetate; this in turn favours the export of malate to the cytosol and its conversion to pyruvate or oxaloacetate, with the formation of NADPH or NADH. The reducing equivalents can be finally retransported into the mitochondria through the $\alpha$-glycerophosphate shuttle, the activity of which increases in ED rats (Iossa et al. 1995), and oxidized through the respiratory chain from complex II onwards. The mechanism described would thus lead to a fall in hepatic metabolic efficiency, with a subsequent wasteful increase in the oxidation of energetic substrates, such as fatty acids. Another possibility is that reducing equivalents are oxidized in the cytosol because of an increased utilization of gluconeogenic substrates which do not generate NADH (alanine), at the expense of those that generate NADH (lactate).

In conclusion, the increased hepatic respiratory activity found in ED rats may represent one of those regulatory mechanisms which are useful to counteract development of obesity.

This work was supported by CNR and MURST.

\section{REFERENCES}

Allard, M. \& LeBlanc, J. (1988). Effects of cold acclimation, cold exposure and palatability on postprandial thermogenesis in rats. International Journal of Obesity 12, 169-178.

American Institute of Nutrition (1977). Report of the American Institute of Nutrition ad hoc committee on standards for nutritional studies. Journal of Nutrition 107, 1340-1348. 
American Institute of Nutrition (1980). Second report of the ad hoc committee on standards for nutritional studies. Journal of Nutrition 110, 1726.

Barr, H. G. \& McCracken, K. J. (1984). High efficiency of energy utilization in "cafeteria" and force-fed rats kept at $29^{\circ} \mathrm{C}$. British Journal of Nutrition 51, 379-387.

Berry, M. N., Clark, D. G., Grivell, A. R. \& Wallace, P. G. (1985). The contribution of hepatic metabolism to diet-induced thermogenesis. Metabolism 34, 141-147.

Berry, M. N., Kun, E. \& Werner, H. V. (1973). Regulatory role of reducing-equivalent transfer from substrate to oxygen in the hepatic metabolism of glycerol and sorbitol. European Journal of Biochemistry 33, 407-417.

Dulloo, A. G. \& Girardier, L. (1993). 24 hour energy expenditure several months after weight loss in the underfed rat: evidence for a chronic increase in whole body metabolic efficiency. International Journal of Obesity 17, 115-123.

Garrow, J. S. (1986). Chronic effects of over and under-nutrition on thermogenesis. International Journal of Vitamin and Nutrition Research 56, 201-204.

Griggio, M. A., Luz, J. \& Carvalho, S. M. T. (1992). The effect of fasting and refeeding on oxygen consumption by rats. Brazilian Journal of Medicine and Biological Research 25, 205-208.

Hill, J. O., Latiff, A. \& DiGirolamo, M. (1988). Effects of variable caloric restriction on utilization of ingested energy in rats. American Journal of Physiology 248, 549-559.

Iossa, S., Liverini, G. \& Barletta, A. (1991). Physiological changes due to cold adaptation in rat liver. Cellular Physiology and Biochemistry 1, 226-236.

Iossa, S., Mollica, M. P., Lionetti, L., Barletta, A. \& Liverini, G. (1995). Hepatic mitochondrial respiration and transport of reducing equivalents in rats fed an energy dense diet. International Journal of Obesity 19, 539 543.

LeBlanc, J., Lupien, D., Diamond, P., Macari, M. \& Richard, D. (1986). Thermogenesis in response to various intakes of palatable food. Canadian Journal of Physiology and Pharmacology 64, 976-982.

Liverini, G., Iossa, S. \& Barletta, A. (1994). Hepatic mitochondrial respiratory capacity in hyperphagic rats. Nutrition Research 11, 1671-1682.

Liverini, G., Iossa, S., Lionetti, L., Mollica, M. P. \& Barletta, A. (1995). Sympathetically-mediated thermogenic response to food in rats. International Journal of Obesity 19, 87-91.

Ma, S. W. Y. \& Foster, D. O. (1986). Starvation-induced changes in metabolic rate, blood flow, and regional energy expenditure in rats. Canadian Journal of Physiology and Pharmacology 64, 1252-1258.

Ma, S. W. Y., Nadeau, B. A. \& Foster, D. O. (1987). Evidence for liver as the major site of diet-induced thermogenesis of rats fed a "cafeteria" diet. Canadian Journal of Physiology and Pharmacology 65, 18021804.

Naim, M., Brand, J. G., Kare, M. R. \& Carpenter, R. G. (1985). Energy intake, weight gain, and fat deposition in rats fed nutritionally controlled diets in a multichoice ("cafeteria") design. Journal of Nutrition 115, 14471458 .

Nobes, C. D., Hay, W. W. \& Brand, M. D. (1990). The mechanism of stimulation of respiration by fatty acids in isolated hepatocytes. Journal of Biological Chemistry 265, 12910-12915.

Pullar, J. D. \& Webster, J. F. (1977).The energy cost of fat and protein deposition in the rat. British Journal of Nutrition 37, 355-363.

Rothwell, N. J. \& Stock, M. J. (1982). Energy expenditure of "cafeteria-fed" rats determined from measurements of energy balance and indirect calorimetry. Journal of Physiology 382, 371-377.

Rothwell, N. J. \& Stock, M. J. (1986), Brown adipose tissue and diet induced thermogenesis. In Brown Adipose Tissue, pp. 269-283 [P. Trayhurn and D. G. Nicholls, editors]. London: Edward Arnold.

Rothwell, N. J., Stock, M. J. \& Tyzbir, R. S. (1982). Energy balance and mitochondrial function in liver and brown fat of rats fed "cafeteria" diet of varying protein content. Journal of Nutrition 112, 1663-1672.

Schwenke, W. D., Soboll, S., Seitz, H. G. \& Seis, H. (1981). Mitochondrial and cytosolic ATP/ADP ratios in rat liver in vivo. Biochemical Journal 200, 405-408.

Seglen, P. O. (1974). Preparation of isolated rat liver cells. Methods in Cell Biology 8, $29-83$.

Sherratt, H. S. A. \& Spurway, T. D. (1994). Regulation of fatty acid oxidation in cells. Biochemical Society Transactions 22, 423-427.

Soboll, S. \& Stucki, J. (1985). Regulation of the degree of coupling of oxidative phosphorylation in intact rat liver. Biochimica et Biophysica Acta 807, 245-254.

Tyzbir, R. S., Kunin, A. S., Sims, N. M. \& Danforth, E. (1981). Influence of diet composition on serum triiodothyronine $\left(\mathrm{T}_{3}\right)$ concentration, hepatic mitochondrial metabolism and shuttle system activity in rats. Journal of Nutrition 111, 252-259. 


\section{Nutrition Keep up to date with all the key worldwide research within the field of human nutrition.}

\section{A botracts and Over 8500 records are added annually from 1200}

English and foreign language journals, conference

\section{Proceedings, annual reports and books. \\ RevieWS Coverage includes: \\ Serical techniques \\ Ser1eS A: - Foods: composition; nutritive value and \\ digestibility; supply; aid and policy \\ Human and : $\quad \begin{aligned} & \text { Physiology and biochemistry } \\ & \text { - Human health and nutrition }\end{aligned}$ \\ Experimental \\ - Nutritional disorders \\ - Therapeutic nutrition}

Stop Press: 1997 volume will also include 2 supplements from key symposia.

ISSN 0309-12

Non-Member Country: $€ 620.00$

1997, Volume 67

Member Country: $€ 496.00$
Monthly

US Dollars: US\$1085.00

Order your 1997 subscription now by contacting CAB INTERNATIONAL on

E-mail: marketing@cabi.org Tel: +44(0)1491832111 Fax: +44(0)1491 826090

\section{Nutrition Abstracts and Reviews Series B: Livestock Feeds and Feeding}

ISSN 0309-135X

Non-Member Country: $€ 395.00$
Keep up to date with all the key worldwide research within the field of animal nutrition.

Over 8500 records are added annually from 1200 English and foreign language journals, conference proceedings, annual reports and books.

Coverage includes:

- Analysis and technology

- Feedstuffs and feeds

- Physiology and biochemistry

- Feeding of animals

- Diet in aetiology of disease

Animals featured include:

Horses, cattle, sheep, goats, pigs, poultry, deer, rabbits, domestic mammals and birds, game and fish

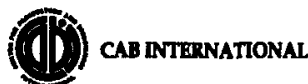

1997, Volume 67

Member Country: $£ 316.00$
Monthly

US Dollars: $\$ 690.00$

Order your 1997 subscription now by contacting CAB INTERNATIONAL on E-mail: marketing@cabi.org Tel: +44 (0) 1491832111 Fax: +44 (0) 1491826090 